\title{
İskelet displazilerinde alt ekstremite deformitelerinin değerlendirilmesi
}

\author{
Evaluating lower extremity deformities in skeletal dysplasias \\ Ozan Ali Erdal ${ }^{1}$, Muharrem İnan ${ }^{2}$ \\ 1 Ortopediatri, İstanbul \\ ${ }^{2}$ İstanbul Üniversitesi Cerrahpaşa Tıp Fakültesi, Ortopedi ve Travmatoloji Anabilim Dalı, İstanbul
}

\begin{abstract}
İskelet displazilerinde alt ekstremite deformiteleri oldukça sık görülür ve hastaların yaşam kalitelerini önemli ölçüde etkiler. Bazı displazi tiplerinde bazı deformiteler daha sık görülmekle birlikte, bir hastadaki deformite uzun kemik fizislerinin asimetrik tutulumu, bacakta bir kemiğin diğerinden farklı bir büyüme hızı göstermesi, eklemlerde genellikle fleksiyon pozisyonundaki kontraktürler ve bağ gevşekliği sonucu gelişen eklem instabiliteleri gibi nedenlere bağ|ı olarak gelişebilir. İskelet displazisi zemininde alt ekstremitelerde sıklıkla görülen deformiteler; koksa vara, koksa valga, genu varum, genu valgum, ayak bileğinde varus ve valgus deformiteleri olarak sıralanabilir. Oluşan deformitelere yaklaşımda, temel deformite düzeltici tedavi yaklaşımlarına hakim olunmalıdır. Her bir bölgenin deformitesinin tedavisi amacıyla farklı kaynaklarda farklı yaklaşımlar önerilmektedir. Hastanın kliniği, deformitenin displazi tipine karakteristik olabilecek özellikleri, hastanın büyüme kapasitesi ile hastadaki kısalığın boyutu değerlendirilerek tedavi kararı verilmelidir. Tedavide ise, akut düzeltme yöntemleri seçilebileceği gibi hemiepifizyodez ile veya eksternal fiksatör sistemleri ile aşamalı düzeltme sağlanabilir. Hastaların tam olarak tahmin edilemeyen büyüme kapasiteleri nedeniyle, tedaviler yetersiz düzeltme ile sonuçlanabildiği gibi uygun tedavi ardından deformitelerde tekrarlama da hastanın büyümesi ile karşılaşılabilecek problemlerdir.
\end{abstract}

Anahtar sözcükler: iskelet displazisi; genu varum; genu valgum; koksa vara; koksa valga; deformite düzeltilmesi
Lower extremity deformities causing decrease in quality of life are commonly seen in patients with skeletal dysplasia. Although some deformities are seen more frequently in specific types of dysplasia, deformities commonly arise from asymmetrical involvement of physes, different longitudinal growth rates of tibia and fibula in the leg, contractures around the joints or joint instabilities due to ligamentous instability. The most common deformities of lower extremities in skeletal dysplasias are coxa vara, coxa valga, genu varum, genu valgum and ankle valgus or varus. When starting to deal with these deformities surgeon should primarily be familiar with general deformity treatment principles. In different studies different treatment protocols are supported for deformities in skeletal dysplasias. Selection out of different correction choices can be done considering clinical condition, future growth potential, magnitude of dwarfism of the patient and characteristic phenotype of a definite dysplasia. Correction can be achieved by either acute correction methods or gradual correction with hemiepiphysiodesis or external fixator systems. Because of lack of definite growth presumption in these patients, sometimes inadequate corrections happen. Also, sometimes a thoroughly corrected deformity might recur in a growing child with skeletal dysplasia.

Key words: skeletal dysplasia; genu varum; genu valgum; coxa vara; coxa valga; deformity correction skelet displazilerinde temel karakteristik özellik olan kısalık ile birlikte, ekstremitelerde açısal bozukluklar, eklem yüzlerinde düzensizlikler ve bağ gevşekliği veya instabiliteleri hemen her hastada değişik derecelerde görülür. Bunlar hastaların yaşam kalitelerini düşürerek oldukça önemli morbiditelere yol açmakta ve sıklıkla cerrahi yöntemlerle düzeltilmeleri söz konusu olmaktadır.
İskelet displazilerindeki ekstremite deformiteleri birkaç nedene bağlı olarak gelişir ve deformiteye yaklaşırken altta yatan olası nedenler ortaya koyulmalıdır. Bu nedenler, uzun kemik fizislerinin asimetrik tutulumu, bacakta veya önkolda bir kemiğin diğerinden farklı bir büyüme hızı göstermesi, eklemlerde genellikle fleksiyon pozisyonundaki kontraktürler ve bağ gevşekliği sonucu gelişen eklem instabiliteleri olarak sıralanabilir.

- İletişim adresi: Prof. Dr. Muharrem İnan, İstanbul Üniversitesi Cerrahpaşa Tıp Fakültesi, Ortopedi ve Travmatoloji Anabilim Dalı, Kocamustafa Paşa, Fatih, İstanbul Tel: 0212 - 4143000 e-posta: muharreminan@hotmail.com

- Geliştarihi: 8 Ağustos $2016 \quad$ Kabul tarihi: 8 Ağustos 2016 
İskelet displazilerinde görülen alt ekstremite deformitelerinin tedavisi temel olarak diğer klinik tablolarda görülen deformitelere yönelik yaklaşımlardan farklı değildir. Bu nedenle, displazi zemininde gelişen bir deformitenin tanısı ve uygun tedavisi için öncelikle genel deformite değerlendirmesi ve tedavi prensipleri ile ilgili bilgi birikimine sahip olunması gereklidir. Ancak, bu hastalık grubunda deformitelerin multifokal ve multiplanar olması, kemik boyutunun küçük ve kalitesinin yetersiz olması, bağ laksitelerinin sıklıkla görülmesi, büyüme potansiyellerinin yetersizliği ve kemikleşmenin geç gerçekleşmesi tedavilerin zorlaşmasına neden olmaktadır. Bu zorlukların bilincinde olarak bir deformitenin varlığının her zaman düzeltilmesini gerektirmeyebileceğini akılda tutmak gerekir. Hastanın duyduğu rahatsızlık ve fonksiyonel kısıtlılığı göz önünde bulundurularak, hastaya en büyük yararı sağlayacağı düşünülen yaklaşımlarda bulunulmalıdır. Bu nedenle, hastaların deformite tedavisi konusunda tecrübeli bir ekip tarafindan takip ve tedavi edilmesi daha uygun olacaktır.

Alt ekstremitelerdeki iskelet displazisi zemininde gelişen deformitelerin ve yaşanacak zorlukların esas olarak etkiledikleri eklemler üzerinden değerlendirilmesi daha anlaşılır olacaktır.

\section{ALT EKSTREMITE DEFORMITELERI VE KARŞILAŞILAN ZORLUKLAR}

Alt ekstremitelerde görülen bir deformite iskelet displazisi zemininde oluştuğunda, kemik uçlarında kemikleşme merkezlerinin gelişimindeki gerilikler nedeniyle, kemik-kıkırdak geçişleri ve belli yaşların altında eklem yüzeyleri direkt röntgen görüntülemeleri ile görülememektedir. Dolayısıyla, çocuk hastalarda ve özellikle iskelet displazisi olan olgularda, yetişkin hastalar için tanımlanmış açısal ölçümlerin yapılması pek mümkün olamamaktadır. ${ }^{[1]}$ Hastaların yaşları küçüldükçe açısal değerlendirmeler zorlaşmakta ve gözlemciler arasındaki tutarlılık azalmaktadır. ${ }^{[2]} \mathrm{Bu}$ nedenle, iskelet displazili hastalarda deformiteler değerlendirilirken düzeltme kararı vermede klinik görünüm, alt ekstremite mekanik aksı, ameliyat öncesi manyetik rezonans (MR) görüntüleme gibi tetkiklerden veya ameliyat öncesindeki/sırasındaki artrografiden yararlanılmalıdır. ${ }^{[1-3]}$

İskelet displazisi zeminindeki deformiteleri değerlendirirken bir diğer problem ise, bu hasta grubunda bir bölgedeki deformitenin düzeltilmesinin aynı kemik veya aynı ekstremitedeki başka bir noktadaki deformitede ilerlemeye yol açabileceği ihtimalidir. Ayrıca, bu hastalarda hangi deformitenin öncelikle düzeltilmesi gerektiği ve hangilerinin bir sonraki aşamaya bırakılabileceği veya düzeltme sonrasında uyum sağlayacağına karar vermek de ayrı bir zorluktur.

Hangi deformitenin düzeltileceğine karar verdikten sonraki aşamada düzeltme yöntemi ve tespit yöntemlerinin, hastaların kemik kalitelerinin yetersiz olması ve kemik boyutlarının da küçük olması göz önünde bulundurularak seçilmesi gerekmektedir. Uygulanacak tedavi ve seçilecek tespit yöntemleri belirlenirken, çoğu iskelet displazisinde eklemlerde erken dönem osteoartrit gelişme yatkınlığı ve bu hastaların genç yaşta kalça ve diz total eklem protezi ameliyatı geçirme olasılıklarının yüksek olduğu akılda tutulmalıdır. ${ }^{[4,5]}$ Uygulanacak düzeltici girişimlerde, gelecekte hastaya uygulanacak bir artroplasti işlemine engel olacak, zorlaştıracak veya protezin hastaya yararını kısıtlayabilecek uygulamalar tercih edilmemelidir.

\section{KALÇA EKLEMINDEKI DEFORMITELER}

İskelet displazisi tanısı olan hastaların büyük bir kısmında (özellikle multipl epifizyel displazi-MED ve spondiloepifizyel displazi-SED tanılı olanlar) erken dönemde kalça osteoartriti gelişmekte ve bu hastalar genç erişkinlik döneminde total eklem protezi ameliyatı geçirmektedirler. ${ }^{[5,6]}$ Kalça eklemi düzeyindeki düzeltici cerrahi girişimler, gelişmiş veya ileride gelişebilecek fonksiyonel kısıtlılığı düzeltmeyi veya engellemeyi amaçlar. Bu nedenle, genellikle akut deformite düzeltme yöntemleri tercih edilmektedir.

\section{Deformitenin Akut Düzeltilmesi}

Deformitelerin akut düzeltmesi, diğer kemik deformitelerinde olduğu gibi uygun planlanmış bir düzeltici osteotomi sonrasında deformitenin düzeltilmesini ve çeşitli tespit yöntemlerinden (Kirschner telleri, alçı uygulaması, plak, intramedüller çivi) birisi ile tespitini kapsar.

İskelet displazisi olan çocuklarda akut düzeltme kararı verilirken, bu hastalık grubuna özgü durumların göz önünde bulundurulması gerekir. Deformitenin tüm bileşenlerine yönelik tedavinin bir defada yapılması hastanın konforunu arttıracak ve tekrarlayan anestezi uygulamalarını da azaltacaktır. Bazı durumlarda $\mathrm{da}$, sadece deformitenin olduğu kemikte bir osteotomi yeterli olmayacak, komşu kemiklerde ek düzeltmeler veya gevşek bağlara yönelik işlemler de gerekecektir. ${ }^{[7]}$

Hangi tespit yöntemi kullanılırsa kullanılsın ve hangi seviyede osteotomi yapılırsa yapılsın, temel amaç ekstremite mekanik aksının ve kemikteki longitudinal aks üzerindeki dizilimin veya torsiyonun normal sınırlar içinde olmasını sağlamaktır. Yetersiz düzeltme yapılan olgularda deformitelerin tekrar etme olasılığının arttığı 
da her zaman akılda tutulmalıdır. Deformite ideal düzeyde düzeltilmiş olsa bile, deformitenin hastanın büyümesi sırasında tekrar aynı yönde oluşabileceği unutulmamalı ve hastalar düzenli takip edilmelidir. ${ }^{[3,8]}$

Deformitenin akut düzeltilmesi ile, cüceliği olan bireylerde uzatma sağlanamaz. Ayrıca, akut düzeltmelerle sinir hasarı, kompartman sendromu (özellikle proksimal tibia osteotomilerinde), kaynama gecikmesi ve kaynamama gibi komplikasyonların görülme ihtimali $\operatorname{artar}^{[8,9]}$

Kalça eklemindeki deformiteler, çoğunlukla koksa vara ve koksa valga şeklinde görülmekte ve bunların akut düzeltilmelerinde femur proksimalinde düzeltici osteotomiler yapılmaktadır. Gerek duyulduğunda, özellikle koksa valgada, buna asetabular osteotomiler de eklenir.

\section{Koksa Vara}

Koksa vara, iskelet displazilerinin çoğunda görülmekle birlikte en sık SED, MED, psödoakondroplazi, kleidokraniyal displazi ve Schmid tipi metafizyel kondrodisplazide görülür. ${ }^{[10]}$ Femur proksimalindeki ossifikasyon merkezlerinin veya femur proksimal fizisinin gelişim geriliği nedeniyle, kalça eklemindeki deformitenin direkt radyografiler ile değerlendirilmesinde zorluk yaşanabilir. ${ }^{[1,2]}$ Bu durumda, trokanter major epifizindeki gelişimin devam ettiği hallerde göreceli olarak trokanterik aşırı büyüme de düşünülebilir. ${ }^{[10]}$ Hastalarda bu nedenle femur başının şekli ve deformitenin ayrıntISı ancak artrografi veya BT/MR gibi yöntemlerle anlaşılabilir. Femur baş-boyun açısı ölçülemediği için de, koksa vara deformitesinin tanınmasında kullanılmak üzere Hilgenreiner-Trokanterik (HT) ve HilgenreinerEpifizyel (HE) açılar tanımlanmıştır. ${ }^{[11,12]}$

Kalça ağrısı, kalçada hareket kısıtıılığı, boyun-şaft açısının $100^{\circ}$ 'den az olması, HE açının $60^{\circ}$ 'den büyük olması ve $\mathrm{HT}$ açının $0^{\circ}$ 'den düşük olması durumunda düzeltme yapılması önerilir. ${ }^{[5,11]}$ Düzeltme işlemi amacıyla femur proksimal valgus osteotomisi yapılır ve bu sırada kalça fleksiyon kontraktürü ve retroversiyonuna da müdahale edilebilir. Tespit yöntemi olarak da femur proksimal plakları veya intramedüller çivileme yöntemleri kullanılabilir.

\section{Koksa Valga}

Koksa valga ve beraberinde, sıklıkla ilerleyici kalça çıkığı mukopolisakkaridozlar (MPS) için karakteristiktir. ${ }^{[3,10]}$ Bu deformitenin takiplerinde, kalçada subluksasyon ile femur başı epifizinde yükseklik kaybı gözlenmekte asetabulumda displazinin de gelişmesi ile femur başının özellikle anterior ve lateral kaplanması bozulmaktadır. Hastaların kalça eklemlerinde takipte, erken yaşta osteoartrit gelişmesiyle fonksiyonel kısıtlılık ilerler. Direkt ön arka nötral pozisyonda ve abduksiyonda pelvis grafilerinin incelenmesi ile femur başının şekli ve örtünmesi ile ilgili fikir sahibi olunduktan sonra, eklemin redükte edilmesi ve düzeltilmesi amacıyla, sıklıkla asetabular osteotomiler ile femur proksimal osteotomileri birlikte yapılmalıdır (Şekil 1). Özellikle MPS olgularında, hastalar tek başına yapılan femur proksimal varus derotasyon osteotomilerinden yarar görebileceği gibi, kalça ekleminin instabil kalabileceği ve revizyon cerrahisi gerekebileceği akılda tutulmalıdır. ${ }^{[3,13]}$

\section{DIZDEKI DEFORMITELER}

Dizde varus veya valgus deformitesinin yanında, çeşitli derecelerde rotasyonel deformiteler, prokurvatum/rekurvatum ve patella subluksasyonu/luksasyonu görülebilir. Özellikle psödoakondroplazide, diz deformitelerinin birden çok planda yerleşmesi sıktır. ${ }^{[10]}$

İskelet displazilerinde dizdeki koronal plan deformiteleri, genellikle endokondral kemikleşmede yetersizliğe, tibia proksimal büyüme plağının asimetrik tutulumuna, daha nadiren femur distal büyüme plağının asimetrik tutulumuna, femur distal epifizinin asimetrik gelişmiş olmasına, menisküs veya bağ anormalliklerine, kapsüler laksiteye veya fibula boyunun aşırı kısa veya uzun olmasına bağlı gelişebilir. ${ }^{[10]}$ Hastanın fazla kilolu olması da deformitenin gelişmesinde bir faktördür. ${ }^{[3,14,15]}$

Dizdeki sıklıkla genu varum veya valgum olarak görülen deformitelerin radyografik incelemelerinde, diz eklemi çevresinde tibiofemoral açı, mekanik lateral distal femoral açı ( $m L D F A)$ ve mediyal proksimal tibial açı (mMPTA) incelenmelidir. Lateral distal tibial açı ise ayrıca ölçülmelidir. Mekanik aks deviyasyonu (MAD) ise, mekanik aksın diz merkezinden uzaklığının milimetre cinsinden ölçümü ile belirlenebileceği gibi, özellikle son zamanlarda alt ekstremite mekanik aksının diz eklem aralığından geçerken diz merkezinden olan uzaklığının mediyal tibial platonun radyografik olarak genişliğine oranının yüzde olarak ifadesi ile tanımlanır. Bu tanımlama lateral eklem aralığı için de aynı şekilde yapılmakta ve lateralde pozitif değer, mediyalde negatif değerler verilmektedir. Mekanik aksın geçebileceği alan dört bölgeye ayrılarak mekanik aks alanları belirlenmiştir: 1. alan, $\% 0-50$; 2. alan, $\% 51-100$; 3. alan, $\% 101-200$ ve 4. alan, \%200'den ötesi olarak tanımlanır. ${ }^{[16]}$ Düzeltme ile, mekanik aksın en fazla lateralde 1. alandan geçmesi hedeflenir. ${ }^{[16,17]}$ Daha önce de bahsedildiği gibi, radyografik ölçümler küçük yaştaki iskelet displazili hastalarda tutarlı sonuçlar vermemektedir ve ek değerlendirmeler gerekebilmektedir. 

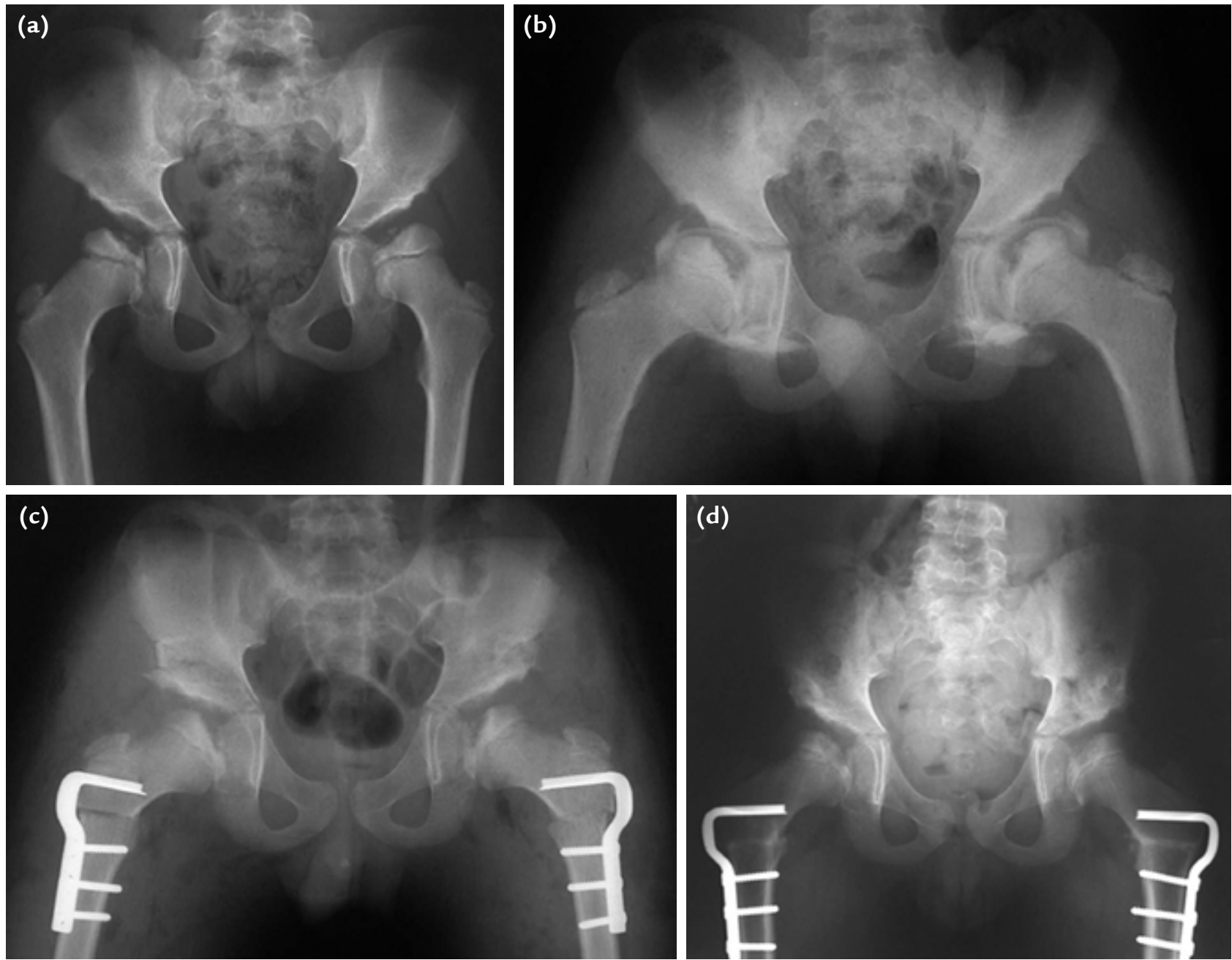

Şekil 1. a-d. Morquio sendromu olan beş yaşında erkek hastada bilateral koksa valga tespit edilmiştir (a). Her iki kalçaya yapılan artrografi ile femur başı örtümü ve başın şekli daha iyi değerlendirilmiştir (b). Hastaya bilateral femur proksimal varus osteotomisi, asetabular osteotomiler yapılmıştır (c). Altı aylık takip grafisi görülmektedir (d).

Diz eklemi çevresindeki deformitelerin düzeltilmesinde ise, akut düzeltme yöntemleri kullanılabileceği gibi aşamalı deformite düzeltme yöntemlerine de başvurulmaktadır. Aşamalı düzeltme yöntemleri, büyümenin yönlendirildiği hemiepifizyodez uygulamaları ve düzeltme ile birlikte uzamanın da sağlanabildiği eksternal fiksatör uygulamaları olarak iki grupta incelenebilir.

\section{Hemiepifizyodez Yöntemleri ile Deformitenin Aşamalı Düzeltilmesi}

Ekstremitenin büyümesinin istenen şekilde yönlendirilmesine olanak veren hemiepifizyodez uygulamaları, aşamalı/tedricen deformite düzeltme yöntemleri içinde uygulaması oldukça basit, fizis yaralanması olasılığı ve implant yetmezliği görülme ihtimali düşük olan seçeneklerdir. ${ }^{[16]}$ En azından bir yıl daha büyüme kapasitesinin olduğu düşünülen hastalarda tercih edilebilen bu seçenek ile, daha büyük ölçekli, osteotomi gerektirecek ve birçok ciddi komplikasyona açık girişimler engellenebilmekte veya geciktirilebilmektedir. $[16,18]$ İskelet displazisi olan olgularda, epifiz ve metafizde deformiteler olmasına rağmen, bu yöntemlerin güvenilir olduğu gösterilmiştir. ${ }^{[16]}$ Ancak, büyüme hızının yavaş olması nedeniyle, düzeltmenin idiyopatik olgulara göre daha yavaş ilerleyeceği de göz önünde bulundurulmalı, işlemin daha erken yaşta yapılması gerekliliği akılda tutulmalıdır. ${ }^{[17,18]} \mathrm{Bu}$ hastalarda tedaviye erken başlansa bile, fizisin kapanma zamanı çoğunlukla tahmin edilemediği için, tam düzeltmeye de ulaşılamayabilir. ${ }^{[17]}$ Fakat, kısmen elde edilmiş olan düzeltme, hastaya fonksiyonel bir yarar sağlamasının 
yanında, ileride gerekecek osteotomi işleminde düzeltme miktarını azaltarak işlemin teknik olarak kolaylaşmasını sağlayabilir.

Hemiepifizyodez için değişik tespit yöntemleri tanımlanmıştır. Bunlardan $U$ çivisi veya staple uygulamaları ile transepifizyel vida uygulamaları, son zamanlarda implant yetmezliği olasılıkları ve fizise kalıcı hasar verilebilmesi korkusu ile popülerliğini kaybederken, epifizyodez plakları (sekiz plaklar) popülerliklerini arttırmaktadır. ${ }^{[16,18]}$ Sekiz plak yapısının esnekliği nedeniyle, uygulama sonrasında erken dönemde vidaların birbirinden uzaklaşması görülmekte, bu sayede de fiziste oluşabilecek kompresyon hasarından uzak durulabilmektedir. ${ }^{[19]}$ Ayrıca, bu uygulamanın staple uygulamasından daha kolay olması da bir tercih nedeni olmuştur. Ancak, diğer yöntemlere göre komplikasyon oranlarının daha az olduğuna dair bir fikir birliği olmadığı gibi, özellikle iskelet displazilerinde komplikasyon oranlarının staple uygulamaları ile aynı olduğu da gösterilmiştir. ${ }^{[19]}$

Hemiepifizyodez için kullanılan tespit materyalinin (staple, vida, plak gibi) amaca ulaşıldıktan sonra çıkartılmasının ardından fizisin davranışı öngörülememektedir. Bu nedenle, hastalar deformitenin tekrarı ihtimali nedeniyle yakın takip altında tutulmalı, gereğinden fazla aşırı düzeltmeden kaçınılmalı ve olası yeniden operasyon ihtimali üzerinde durulmalıdır. ${ }^{[17,18]}$

\section{Eksternal Fiksatör Yöntemleri ile Deformitenin Aşamalı Düzeltilmesi}

Eksternal fiksatör uygulamaları ile yapılan aşamaI deformite düzeltilmesinde, tek bir seans cerrahi ve sonrasındaki basamaklar ile iskelet displazili olgularda multiplanar ve multifokal deformiteler aşamalı olarak düzeltilebilir. Düzeltme işleminin yanında, ekstremitede uzatma da yapılabilmesi önemli bir avantajdır. $\mathrm{Bu}$ yöntemlerden olan tek düzlemli (monolateral) eksternal fiksatör uygulamaları, rotasyonel deformitesi olmayan, tek düzlemde oluşmuş, göreceli olarak daha basit deformiteleri düzeltmekte kullanılırken, geleneksel Ilizarov sirküler eksternal fiksatör sistemleri veya bunların bilgisayar destekli modern şekilleri ise daha karmaşık deformitelerin düzeltilmesinde kullanılmaktadır. ${ }^{[9,20]} \mathrm{Bu}$ yöntemler ile akut düzeltmenin olası komplikasyonları ile karşılaşılmamış olup, daha az periosteal veya nörovasküler hasar ile amaca ulaşılmış olur. Öte yandan, operasyon sonrası hasta uyumu ve hastalar veya hekim için oldukça karmaşık sayılabilecek takip ve düzeltme aşamaları bu uygulamaların dezavantajlarıdır. ${ }^{[21]}$ Hangi yöntem kullanılırsa kullanılsın, eksternal fiksatör kullanımına bağlı olarak uygulanan tellerin veya vidaların eğilmesi, kırılması, yumuşak doku irritasyonu ve pin dibi enfeksiyonları karşılaşılabilen problemlerdir. Ayrıca, fiksatörün çıkartılmasından sonra oluşan kallusun güçsüzlüğü, bağ laksitesi ve çevre kemiklerdeki diğer deformiteler nedeniyle, deformitenin tekrar edebileceği de gösterilmiştir. ${ }^{[9,20]}$ Uzatma veya deformite düzeltme sırasında erken konsolidasyon yaşanması ve işlemin beklenenden erken sonlandırılması ve ek cerrahi gereksinimi, diğer problemlerdir. Bu komplikasyonun, monolateral eksternal fiksatörlere göre llizarov ve benzeri sirküler eksternal fiksatör uygulamalarında daha nadir olduğu gösterilmiştir. Bunun nedeni olarak da, sirküler sistemlerin düzeltme veya uzatma için uyguladıkları gücün kemiğe daha muntazam aktarılması olduğu düşünülmüştür. ${ }^{[22]}$

Uzatmanın ön planda olduğu tedavilerde, uzatma sonunda deformitenin tekrar etmesinin önüne geçilmesi için, deformitenin akut düzeltilip intramedüller çivi ile tespiti ve bu çivi üzerinden eksternal fiksatör ile aşamalı uzatma sonucunda başarılı sonuçlar elde edilmiştir. ${ }^{[21]}$

Eksternal fiksatör sistemleri ile tedricen deformite düzeltmesine uzatma da dahil edildiğinde, özellikle tibia boyunun \%40'ını, distal tibiada ise \%15'ini aşan uzatmalarda ayak bileğinde ekin kontraktürü gelişebileceği unutulmamalı ve ayağın plantigrad basışını sağlamak üzere, ayağa da bir fiksatör halkası yerleştirilerek tedricen dorsifleksiyon kazandırılması veya korunması gerekliliği göz önünde bulundurulmalıdır. ${ }^{[9,20]}$

\section{Genu Varum}

Genu varum, özellikle akondroplazi, Schmid tipi metafizyel kondrodisplazi, MED ve psödoakondroplazi ile birlikte görülür. ${ }^{[5,10]} \mathrm{Bu}$, akondroplazili hastalarda en sık karşılaşılan ve tedavi edilmesi konu olan en sık deformitedir. ${ }^{[5,10,17]}$ Akondroplazili çocuklarda, erkeklerde genu varum görülme sıklığının kızlara göre daha yüksek olabileceği 48 hastalık bir çalışma ile gösterilmiştir. ${ }^{[23]}$

Akondroplazili olgularda 2-6 yaş arasında genu varum, sıklıkla proksimalde fibula uzaması, lateral kollateral bağın laksitesi ve tibia vara ile birlikte ortaya çıkar. Yaş ilerledikçe, distal fibular uzama ve distal tibial varus ile bacaktaki eğrilik daha da belirginleşir. ${ }^{[4,14]}$

Genu varum, radyografik olarak normalde $0-6^{\circ}$ valgusta olan anatomik tibiofemoral aksın varusta olma durumu veya alt ekstremite mekanik aksının diz eklemi merkezi yerine mediyal eklem aralığından geçmesi olarak tanımlanabilir. ${ }^{[23]}$

Genu varum deformitesi olan bir bireyde, tıpkı pek çok iskelet displazisinde olduğu gibi, erken dönemde diz osteoartriti gelişmesi beklenebilir. Ancak, akondroplazili 

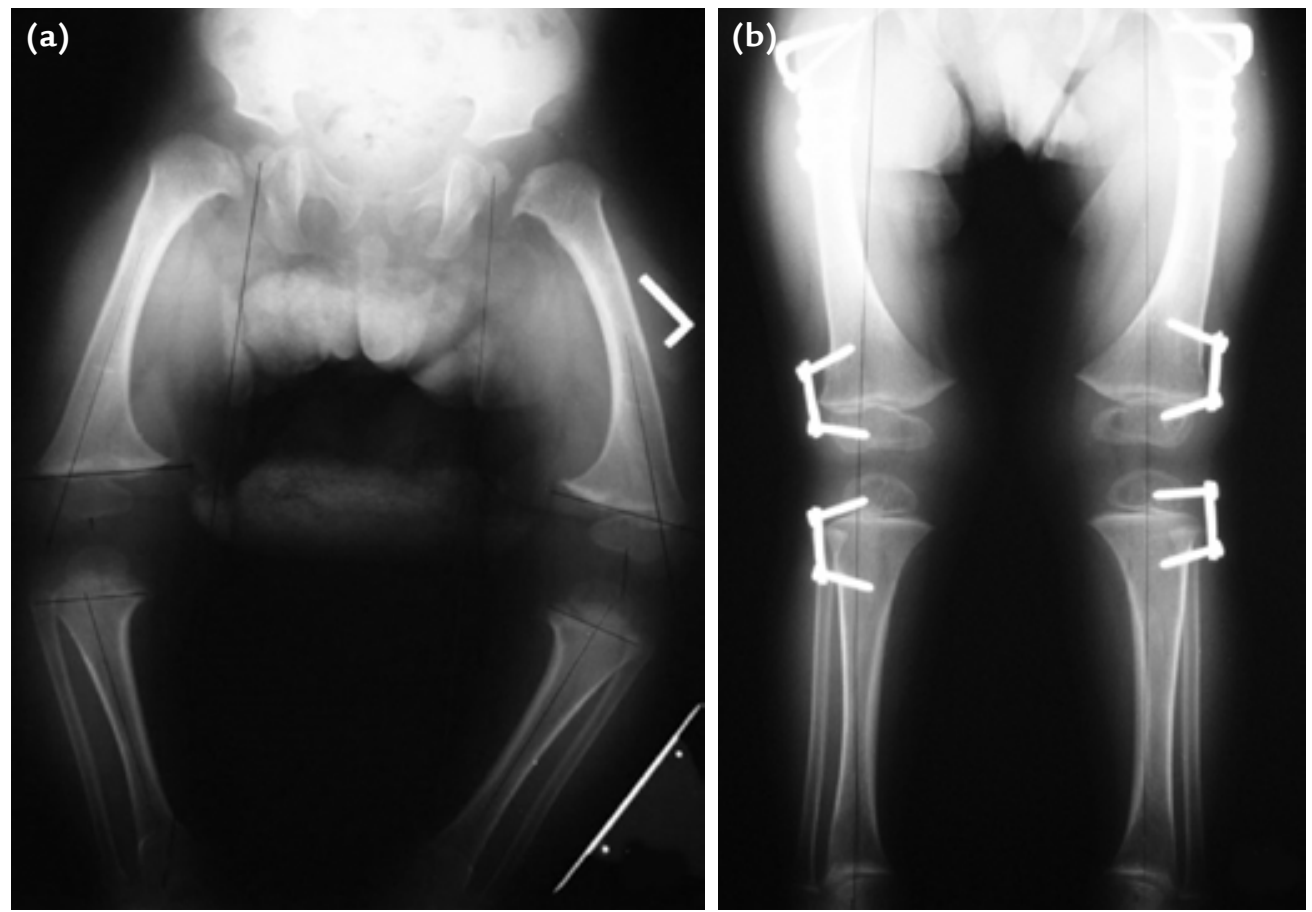

Şekil 2. a, b. Bilateral genu varum ve bilateral koksa varası olan akondrolazili üç yaşında kadın hasta. Bilateral femur distal ve tibia proksimal lateral hemiepifizyodez uygulaması ve bilateral femur proksimal valgus osteotomisi sonrası takip grafileri görülmektedir $(\mathbf{a}, \mathbf{b})$.

bireylerde diz osteoartriti nadiren gelişmekte ve üstelik diz eklemi sıklıkla fonksiyonel kısıtlılık yaratmamaktadır. Bu hastalarda tekrar eden diz veya ayak bileği ağrıları ise sıktır. Aksine, psödoakondroplazide genu varum ile birlikte osteoartrite yatkınlık artmışır. ${ }^{[4,5]}$

Hastalarda deformite $10^{\circ}$ 'nin üzerindeyse, ağrıya neden olduğunda, deformite ilerlemeye devam ettiğinde, yürüme sırasında gövdede laterale kayma tespit edildiğinde düzeltilmelidir. ${ }^{[5,18]}$ Bazı durumlarda, hastaların boy kısalığının yanında dizlerdeki deformiteye yönelik de kozmetik kaygıları olabilmektedir. Küçük çocuklardaki hafif deformitelerde, fibulanın aşırı uzun olduğu olgularda proksimal fibular epifizyodez veya proksimal fibular kısaltma ile deformitenin düzeltilebileceği önerilmiştir. ${ }^{[4,14]}$ Başka bir yayında ise, akondroplazili olgularda genu varumun sıklıkla gözlenen fibula aşııı uzaması ile ilişkili olmadığı ve tedavinin deformitenin olduğu femur veya tibiaya yöneltilmesi gerektiği gösterilmiştir. [23] Proksimal tibia veya distal femurda yeterli büyüme kapasitesi var ise, deformitenin lateral hemiepifizyodez ile aşamalı olarak düzeltilebilmesi mümkündür.

Akut düzeltme yöntemleri sonrasında büyümeye devam eden çocukta görülebilen deformitenin tekrarı ve revizyon cerrahisi ihtiyacı, hemiepifizyodez yöntemlerinin tercihini arttırmaktadır (Şekil 2). ${ }^{[18]}$ Ancak, bu tedavi ile tibial rotasyon düzeltilememekte ve oblik plan deformitelerinin düzeltilmesi zorlaşmaktadır. İdiyopatik genu varum olgularında kendiliğinden gerileme ihtimali nedeni ile, düzeltme genellikle sekiz yaşından sonra önerilirken, iskelet displazili olgularda büyüme hızları yavaş, düzeltme için gerekli süre uzun olduğu için, daha erken yaşlarda hemiepifizyodez ile düzeltme tercih edilmelidir. İmplantların ise, büyümesi bir iki yıl kalmış bireylerde mekanik aks diz merkezine yaklaştığında, daha uzun süre kaldığında ise karşı tarafın 1. alanına ulaştığında çıkartılması, daha fazla aşırı düzeltmelerden kaçınılması uygun bulunmuştur. ${ }^{[16,17]}$

Genu varumda deformitenin akut düzeltme ile düzeltilmesinde, osteotominin amaca yönelik yapılması ile kemikteki varus dışındaki diğer deformitelere de çözüm üretilmiş olmaktadır. Genu varumun lateral kollateral bağ laksitesi ile birlikte olduğu durumlarda, proksimal tibial osteotominin yanında, bağın kısaltılması veya fibula osteotomisi ve fibula proksimalinin distal translasyonu ile deformite düzeltmesi önerilir. ${ }^{[7]} \mathrm{Bu}$ durumda veya ileri derecede deformiteler için, llizarov ve benzeri eksternal fiksatör sistemleri ile aşamalı düzeltme önerilir. ${ }^{[7,22]}$ Multifokal tibia deformiteleri ile birlikte rotasyonel problemler, aynı seansta yapılan iki farklı osteotomi ile de aşamalı olarak düzeltilebilir. ${ }^{[20]}$ 

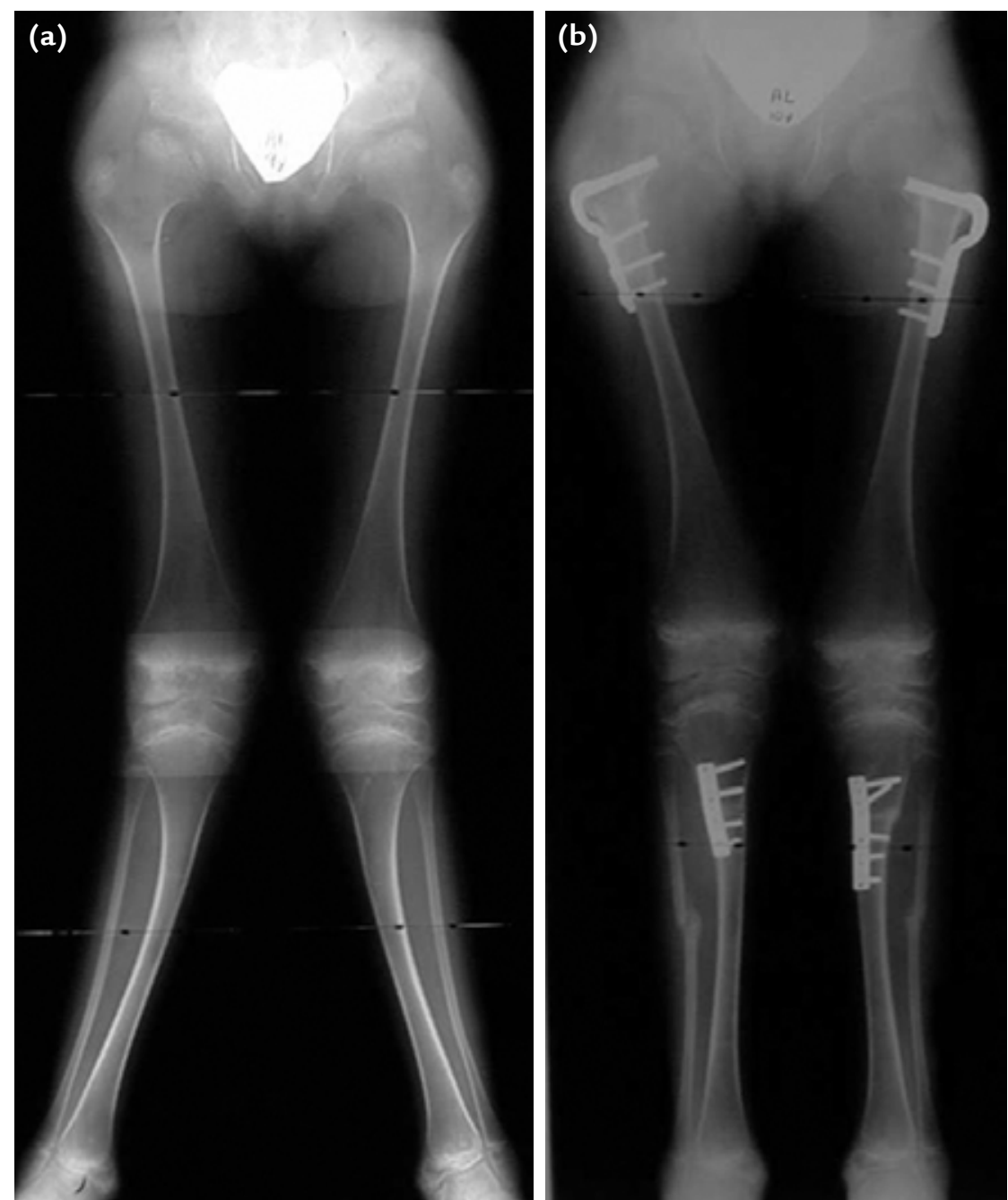

Şekil 3. a, b. Bilateral genu valgum ve bilateral koksa varası olan psödoakondroplazi tanılı dokuz yaşında erkek hasta. Bilateral tibia proksimal düzeltici osteotomisi ve bilateral femur proksimal valgus derotasyon osteotomisi yapılmıştır (a, b).

\section{Genu Valgum}

Genu valgum ise, daha sıklıkla diastrofik displazi, MPS, MED, SED ve psödoakondroplazi olgularında gözlenir. ${ }^{[10]}$ Genu valgum, anatomik tibiofemoral açının $7^{\circ}$ 'nin üzerinde valgusta olduğu açısal deformite olarak tanımlanabilir. On derecenin üzerinde olduğunda veya mekanik aksın lateralde 2 . veya 3 . mekanik aks alanlarından geçmesi durumunda, yürüme mekaniği bozulmakta, buna diz önü ağrısı, oraklayarak yürüme veya patellofemoral instabilite de eşlik edebilmektedir. Bu durumda, mekanik aksın normale getirilmesi amacıyla düzeltici cerrahi önerilir. ${ }^{[15,18]}$

Düzeltici cerrahilerde amaç, alt ekstremite mekanik aksını en fazla karşı tarafın 1. alanından geçecek şekilde ayarlamaktır. Kalan büyüme zamanı bir iki yıldan daha uzun olan olgularda bu seviyedeki aşırı düzeltme tercih edilirken, daha kısa süre büyümesinin kaldığı düşünülen hastalarda mekanik aksın diz merkezinden geçirilmesinin planlanması uygun olacaktır. ${ }^{[16,17]}$

Yeterli büyüme potansiyeli olan, iskelet gelişimine en az bir yıl kalmış olgularda, distal femoral veya proksimal tibial mediyal hemiepifizyodez ile, genu valgum deformitesi düzeltilebilir ${ }^{[3,15,16]} \mathrm{Bu}$ tedavinin uygulanamayacağı olgularda ise, düzeltici osteotomilerle valgus deformitesi düzeltilirken aynı anda sagittal plandaki fleksiyon kontraktürü ile transvers plandaki rotasyonel problemler de akut veya aşamalı yöntemlerle çözülebilir (Şekil 3 ve 4). ${ }^{16,24]}$ Displazi zemininde düzeltmeler sonrasında, tibia veya femurda valgus 

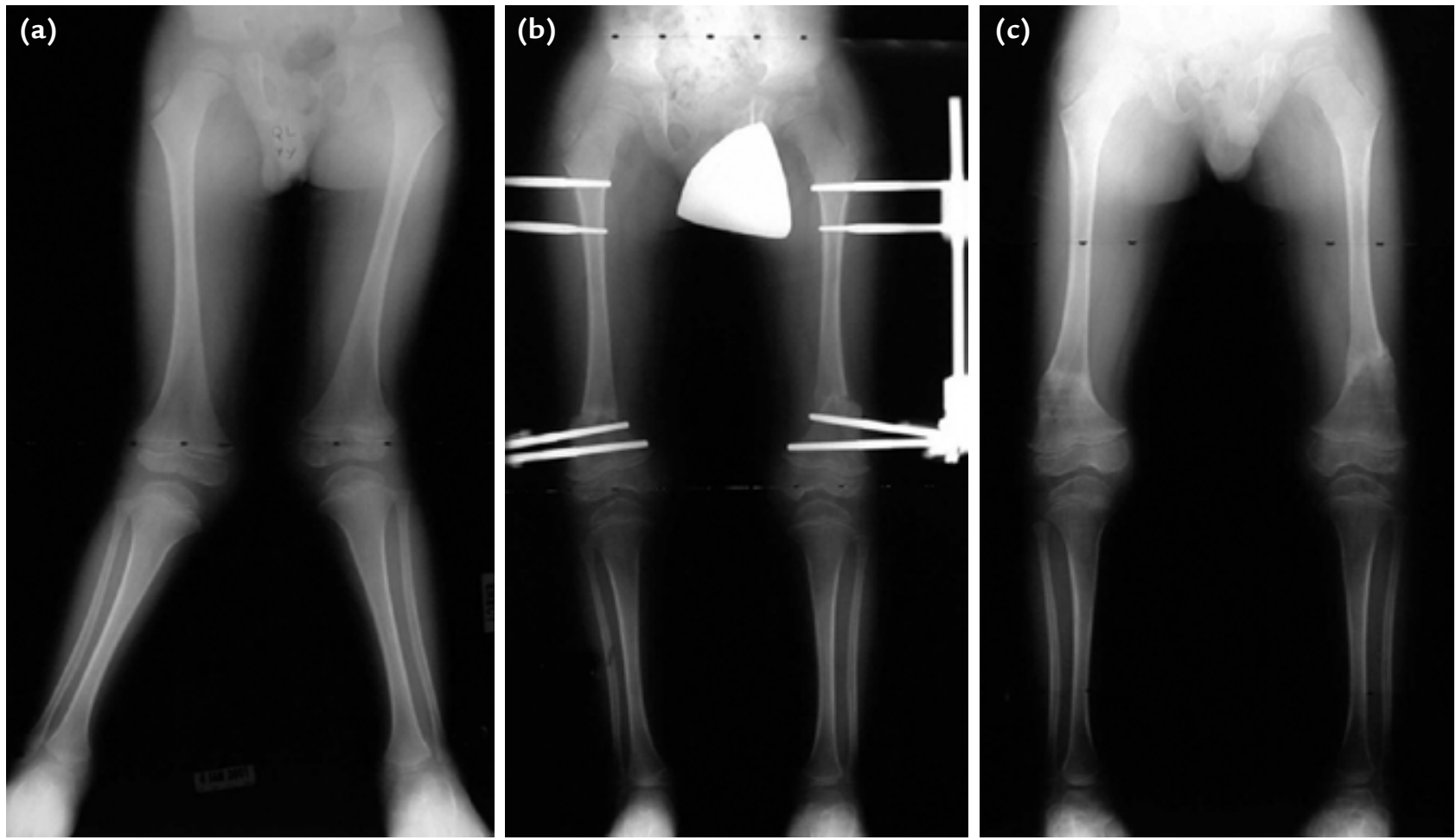

Şekil 4. a-c. Bilateral genu valgumu olan spondiloepifizyel displazi tanılı dört yaşında erkek hasta. Mevcut femur distal valgus deformitesi için akut düzeltme ve eksternal fiksatör ile tespit yapılmış olan hastanın bir yıllık takip grafisi sunulmuştur (a-c).

deformitesinin tekrar etme olasılığının yüksek olduğu gözlenmiş̧ir. ${ }^{[3]}$

\section{Patella Luksasyonu/Subluksasyonu}

Patella çıkığı, iskelet displazilerinde sıklıkla karşılaşılan bir durumdur. Diastrofik displazi, MED ve SED olgularında daha sık karşılaşılır. Özellikle bağ laksitesine bağlı olabileceği gibi, epifizin anterolateral kondil kısmının asimetrik olarak az gelişmiş olmasına da bağı olabilir. Sıklıkla genu valgum deformitesi ile beraber görülür. Genu valgum deformitesinin kemiksel kaynakları çözülürken, patella çıkığının redüksiyonuna yönelik cerrahiler de erkenden planlanmalıdır. Mediyal plikasyon ve lateralde iliotibial bant ve biseps femoris gevşetmeleri ile, sıklıkla patellar tendon yapışma yerinin mediyalizasyonuna da başvurulmaktadır. ${ }^{[3,10]}$

\section{AYAK BILEĞiNDEKI DEFORMITELER}

İskelet displazilerindeki en sık ayak bileği deformitesi, fibulanın kısalığına bağlı olarak gelişen ayak bileğinde valgus deformitesidir. ${ }^{[10]}$ Bu deformiteye oldukça sık rastlanması nedeniyle, tedavi kararı verirken hastanın aktivite düzeyine etkisi göz önünde bulundurulmalıdır. Yürümeye engel teşkil eden ve hastanın tolere edemediği bir valgus deformitesi için düzeltme düşünülmelidir. Tedavisi genellikle tibia-fibula distal düzeltici osteotomileri ile akut veya aşamalı olarak yapılır. Yeterli büyüme potansiyeli olduğu düşünülen hastalarda deformitenin, tam veya kısmi yivli vida ile distal mediyal tibiaya hemiepifizyodez uygulaması ile de düzeltilebileceği gösterilmiştir. ${ }^{[3,16,24]}$

Daha nadir görülen ayak bileğinde varus deformitesi, genellikle akondroplazi, hipokondroplazi ve metafizyel kondrodisplazi olgularında oluşur. ${ }^{[5,10]}$ Akondroplazi olgularında, sekiz yaşından sonraki ileri çocukluk çağında fibula ile tibia boyu arasındaki farkın özellikle distalde artması ile birlikte distal tibial varus görülür ve genu varum görünümünü arttırır. Bu hastalarda proksimalden yapılan deformite düzeltme işlemleri kabul edilebilir bir düzeltme sağlasa da, distal tibial osteotomi ve distal fibular kısaltma osteotomileri önerilir. Bu yaş grubunda, daha az girişimsel bir işlem olarak, distal fibular epifizyodez ile distal tibial varusun ilerlemesinin önüne geçilebileceği de bildirilmiştir. ${ }^{[7,14]}$

\section{AYAKTAKI DEFORMITELER}

Ayak deformiteleri, özellikle diastrofik displazi, SED ve MPS olgularında sıktır. ${ }^{[3,10]}$ Deformiteler, 
esnek olabildikleri gibi oldukça sert de olabilir. Bunlar, genellikle sadece ligamentöz kaynaklı olmayıp kemiksel veya eklem kıkırdaklarından kaynaklı deformiteler de olabilir. Diastrofik displazide ayak deformiteleri genellikle sert iken, SED olgularında genellikle esnektir. ${ }^{[10]}$ Metatarsus adduktus veya pes ekinovarus gibi deformiteler esnek yapıda olduklarında seri alçılamalar veya ortezler ile düzeltilmeye çalışılırken, başarısızlık oranları idiyopatik olgulardan daha sıktır. Sert olgularda ise, tedavi mevcut deformiteye özel tasarlanmakta ve yumuşak doku gevşetmeleri veya tendon transferleri yanında orta ayak osteotomileri veya artrodezler de tedavi seçenekleri arasında yer almaktadır. ${ }^{[3,10,25,26]}$

Özellikle diastrofik displazi hastalarında tekrar eden ekin kontraktürleri de sıktır ve tekrarlayan yumuşak doku gevşetmeleri sonunda başarısızlıkla sonuçlanır. Bunun diz ve kalçadaki fleksiyon kontraktürlerine bağlı tekrar ettiği düşünülmektedir. Bu nedenle, hastaların ekin kontraktürü düzeltilmesi planlanırken, bu kontraktürlerin de çözümlenmesi önerilmektedir. İleri evrede kontraktürü olan olgularda ise, tibia ve fibula distal ekstansiyon osteotomileri uygulanması tercih edilebilir. ${ }^{[6]}$

\section{KAYNAKLAR}

1. Fraser SC, Neubauer PR, Ain MC. The role of arthrography in selecting an osteotomy for the correction of genu varum in pediatric patients with achondroplasia. J Pediatr Orthop B 2011;20(1):14-6. Crossref

2. Inan M, Jeong C, Chan G, Mackenzie WG, Glutting J. Analysis of lower extremity alignment in achondroplasia: interobserver reliability and intraobserver reproducibility. J Pediatr Orthop 2006;26(1):75-8.

3. Lee ST, Song HR, Mahajan R, Makwana V, Suh SW, Lee SH. Development of genu varum in achondroplasia: relation to fibular overgrowth. J Bone Joint Surg Br 2007;89(1):57-61.

4. Dhawale AA, Thacker MM, Belthur MV, Rogers K, Bober MB, Mackenzie WG. The lower extremity in Morquio syndrome. J Pediatr Orthop 2012;32(5):534-40. Crossref

5. Thacker MM, Davis ED, Ditro CP, Mackenzie W. Limb lengthening and deformity correction in patients with skeletal dysplasias. In: Sabharwal S, editor. Pediatric Lower Limb Deformities. Principles and Techniques of Management. Switzerland: Springer; 2016. p.313-32.

6. Kopits SE. Orthopedic complications of dwarfism. Clin Orthop Relat Res 1976;(114):153-79.

7. Beals RK, Stanley G. Surgical correction of bowlegs in achondroplasia. J Pediatr Orthop B 2005;14(4):245-9.

8. Payman KR, Patenall V, Borden P, Green T, Otsuka NY. Complications of tibial osteotomies in children with comorbidities. J Pediatr Orthop 2002;22:642-4.

9. Kim SJ, Cielo B, Song SH, Song HR, Song SY. Gradual bilateral genu varum correction in skeletal dysplasia using the llizarov method. J Orthop Sci 2011;16(4):405-12. Crossref

10. Shapiro F. Skeletal Dysplasias. In: Shapiro F, editor. Pediatric Orthopedic Deformities. Switzerland: Springer; 2016. p. 205-409.
11. Oh CW, Thacker MM, Mackenzie WG, Riddle EC. Coxa vara: a novel measurement technique in skeletal dysplasias. Clin Orthop Relat Res 2006;447:125-31.

12. Crossan JF, Wynne-Davies R, Fulford GE. Bilateral failure of the capital femoral epiphysis: bilateral Perthes disease, multiple epiphyseal dysplasia, pseudoachondroplasia, and spondyloepiphyseal dysplasia congenita and tarda. J Pediatr Orthop 1983;3(3):297-301.

13. Kanazawa $T$, Yasunaga $Y$, Ikuta $Y$, Harada A, Kusaka O, Sukegawa K. Femoral head dysplasia in Morquio disease type A. bilateral varus osteotomy of the femur. Acta Orthop Scand 2001;72(1):18-21.

14. Stanley G, McLoughlin S, Beals RK. Observations on the cause of bowlegs in achondroplasia. J Pediatr Orthop 2002;22(1):112-6.

15. Odunusi E, Peters C, Krivit W, Ogilvie J. Genu valgum deformity in Hurler syndrome after hematopoietic stem cell transplantation: correction by surgical intervention. J Pediatr Orthop 1999;19(2):270-4.

16. Yilmaz G, Oto M, Thabet AM, Rogers KJ, Anticevic D, Thacker MM, Mackenzie WG. Correction of lower extremity angular deformities in skeletal dysplasia with hemiepiphysiodesis: a preliminary report. J Pediatr Orthop 2014;34(3):336-45. Crossref

17. Cho TJ, Choi IH, Chung CY, Yoo WJ, Park MS, Lee DY. Hemiepiphyseal stapling for angular deformity correction around the knee joint in children with multiple epiphyseal dysplasia. J Pediatr Orthop 2009;29(1):52-6. Crossref

18. Boero $\mathrm{S}$, Michelis MB, Riganti S. Use of the eight-plate for angular correction of knee deformities due to idiopathic and pathologic physis: initiating treatment according to etiology. J Child Orthop 2011;5(3):209-16. Crossref

19. Wiemann JM 4th, Tryon C, Szalay EA. Physeal stapling versus 8-Plate hemiepiphysiodesis for guided correction of angular deformity about the knee. J Pediatr Orthop 2009;29(5):4815. Crossref

20. Vaidya SV, Song HR, Lee SH, Suh SW, Keny SM, Telang SS. Bifocal tibial corrective osteotomy with lengthening in achondroplasia: an analysis of results and complications. J Pediatr Orthop 2006;26(6):788-93.

21. Bilen FE, Kocaoglu M, Eralp L, Balci HI. Fixator-assisted nailing and consecutive lengthening over an intramedullary nail for the correction of tibial deformity. J Bone Joint Surg Br 2010;92(1):146-52. Crossref

22. Myers GJ, Bache CE, Bradish CF. Use of distraction osteogenesis techniques in skeletal dysplasias. J Pediatr Orthop 2003;23(1):41-5.

23. Ain MC, Shirley ED, Pirouzmanesh A, Skolasky RL, Leet Al. Genu varum in achondroplasia. J Pediatr Orthop 2006;26(3):375-9.

24. Miura $H$, Noguchi $Y$, Mitsuyasu $H$, Nagamine R, Urabe K, Matsuda S, Iwamoto Y. Clinical features of multiple epiphyseal dysplasia expressed in the knee. Clin Orthop Relat Res 2000;(380):184-90.

25. Weiner DS, Jonah D, Kopits S. The 3-dimensional configuration of the typical foot and ankle in diastrophic dysplasia. J Pediatr Orthop 2008;28(1):60-7.

26. Ryoppy S, Poussa M, Merikanto J, Marttinen E, Kaitila I. Foot deformities in diastrophic dysplasia. An analysis of 102 patients. J Bone Joint Surg Br 1992;74(3):441-4. 